\title{
RNF213 gene silencing upregulates transforming growth factor $\beta 1$ expression in bone marrow-derived mesenchymal stem cells and is involved in the onset of Moyamoya disease
}

\author{
CHANGSHUI WANG ${ }^{1}$, CUILIAN SUN ${ }^{1}$, YUESHU ZHAO $^{1}$, HUIMIN SONG $^{1}$, \\ ZHENGYOU LI $^{2}$, FENG JIN ${ }^{1}$ and CHANGMENG CUI ${ }^{1}$ \\ ${ }^{1}$ Department of Neurosurgery, Affiliated Hospital of Jining Medical University, Jining, Shandong 272000; ${ }^{2}$ Department of \\ Neurosyrgery, Shandong Province Western Hospital, Shandong Province ENT Hospital, Jinan, Shandong 250022, P.R. China
}

Received August 27, 2020; Accepted December 12, 2020

DOI: $10.3892 /$ etm.2021.10456

\begin{abstract}
Moyamoya disease (MMD) is a chronic and progressive cerebrovascular occlusion disease, the precise etiology of which is poorly understood. Ring finger protein 213 (RNF213) has been previously identified as a susceptibility gene that serves an important role in angiogenesis, where it has been shown to be closely associated with the onset of MMD. Patients with MMD exhibit increased expression levels of various pro-inflammatory molecules and angiogenic factors. Under certain conditions, bone marrow mesenchymal stem cells (BMSCs) have the ability to differentiate to form neuron-like and microglia-like cells. In the present study, a total of $40 \mathrm{MMD}$ patients and 40 healthy individuals were enrolled. ELISA assays revealed that the expression of serum vascular endothelial growth factor (VEGF) and transforming growth factor $\beta 1$ (TGF- $\beta 1$ ) were higher than that in healthy controls. Furthermore, rat BMSCs (rBMSCs) were isolated and cultured using the whole bone marrow adherence method, which were then phenotyped using flow cytometry. Osteogenic and adipogenic differentiation were determined by using Alizarin red and oil red O staining, respectively. RNF213 was knocked-down using a lentivirus-mediated short hairpin RNA system in passage three rBMSCs, and successful transfection of the RNF213 was confirmed by RT-qPCR and fluorescence imaging. The expression levels of VEGF and TGF- $\beta 1$ in these rBMSCs were measured on days 7 and 14, respectively. The results demonstrated that RNF213 knockdown upregulated TGF- $\beta 1$ at both protein and mRNA levels, but did not exert
\end{abstract}

Correspondence to: Dr Changmeng Cui or Professor Feng Jin, Department of Neurosurgery, Affiliated Hospital of Jining Medical University, 89 Guhuai Road, Jining, Shandong 272000, P.R. China

E-mail: cmcuidr1989@163.com

E-mail: jinfeng1223@mail.jnmc.edu.cn

Key words: Moyamoya disease, ring finger protein 213, bone marrow mesenchymal stem cells, vascular endothelial growth factor, transforming growth factor $\beta 1$ any effect on VEGF gene expression. In conclusion, these findings suggested that that RNF213 knockdown may contribute to aberrant TGF- $\beta 1$ expression via a pathway that remains to be unidentified, indicating that quantitative changes in RNF213 gene expression may serve an important role in the pathogenesis of MMD.

\section{Introduction}

Moyamoya disease (MMD) was first defined by Suzuki and Takaku in 1999 (1) and presents as the presence of an abnormal vascular network at the base of the brain. MMD is characterized by progressive stenosis and even occlusion of the terminal portion of the bilateral internal carotid and intracerebral arteries (2). The most common symptoms of MMD include headache, ischemia and hemorrhage (3). The incidence of MMD in Japan has increased from 0.35 per 100,000 individuals in 1995 to 0.94 per 100,000 individuals in 2006 (4). MMD has mostly been reported to exhibit a high incidence in various East Asian populations, including Chinese, Japanese and Korean (5). Although basic studies, including those using genomic and proteomic approaches, have been performed, the precise etiology of MMD remains unclear.

An increasing number of studies have demonstrated that, although the occurrence and development of MMD are multifactorial, genetic factors are closely associated with the pathophysiology of MMD (6,7). More recently, a variety of loci were found to be involved in MMD, including 17q25, 8q23, 6q25 and 3p24-p26 (8-11). In particular, genome-wide and locus-specific association studies have identified ring finger protein 213 (RNF213) in the 17q25-ter region as a novel susceptibility gene for MMD (12). RNF213 has been shown to serve an important role in angiogenesis and is closely associated with the onset of MMD (13-15). A previous study has revealed that the large trunk arteries have irregular diameters and abnormal sprouting occurs in zebrafish following RNF213 knockdown (16). In addition, MMD is also frequently accompanied with hypertension (17). A possible reason for this is that changes in RNF213 expression can result in increased blood pressure, which aggravates 
intracranial hemodynamic disorders further and induce the formation of 'smoky' blood vessels $(18,19)$. A homozygous variant of RNF213 is considered to be the most pathogenic and was found to be significantly associated with severe manifestations of MMD (20). The mutation rate of the rs112735431 locus of RNF213 was high among Japanese patients with familial and sporadic Moyamoya (21), with similar findings observed in the Han Chinese population $(22,23)$. RNF213 has also been recognized as an effective biomarker for predicting MMD prognosis (24). Alternatively, a variety of biomarkers and angiogenic factors, including vascular endothelial growth factors (VEGF), cytokines, such as matrix metallopeptidase 9 , have been previously reportedly implicated in MMD (25). Based on this evidence, it was hypothesized that the RNF213 gene silencing may promote the abnormal expression of MMD-associated factors through a specific gene pathway, leading to the development of MMD.

Mesenchymal stem cells (MSCs) possess high self-renewal abilities and multidirectional differentiation potentials (26). In certain conditions, they can differentiate to form neuron-like and microglia-like cells $(27,28)$ MSCs has been reported not only to increase endothelial cell growth, but also to promote skin wound healing through vascular endothelial growth factor C-mediated angiogenesis $(29,30)$. In addition, MSCs have the advantage of being easily obtained and reportedly exert neuroprotective effects against ischemic brain damage (31), making their use increasingly popular for basic research and clinical studies. Cerebral hemorrhage and ischemia are common pathophysiological states in neurosurgical diseases, including MMD and subarachnoid hemorrhage (32). After cerebrovascular events, neurocognitive function is impaired (33). MSCs has been shown to confer beneficial effects against cerebrovascular diseases (34). It has also been reported that there were no significant complications within 5 years of MSC treatment for ischemic stroke (35). However, to the best of our knowledge, no studies have focused on the effects of the susceptible gene RNF213 on MMD by using MSCs. The rat bone marrow mesenchymal stem cells (rBMSCs) were therefore selected for the present in vitro study, where the aim was to determine the effects of RNF213 silencing on the expression of VEGF and transforming growth factor $\beta 1$ (TGF- $\beta 1$ ) in rBMSCs and to investigate the association between the RNF213 gene expression and MMD occurrence.

\section{Materials and methods}

Subjects. A total of 40 patients with MMD were enrolled into the Departments of Neurosurgery and Neurology of the Affiliated Hospital of Jining Medical University (Jining, China) between September 2014 and April 2015. The selection criteria were as follows: i) Digital subtraction angiography (DSA) confirming MMD and patients meeting the Guidelines for Diagnosis and Treatment of Moyamoya Disease (Spontaneous Occlusion of the Circle of Willis) (36); ii) CT or MRI examination confirming cerebral infarction and cerebral hemorrhage or ischemia; iii) patients with complete clinicopathological data. The exclusion criteria were as follows: i) Patients with a history of autoimmune disease or neuropsychiatric diseases; ii) patients with intracranial tumors, severe brain injury and cardiovascular disease; iii) use of any medications that could affect cognitive function. An additional 40 healthy individuals were recruited as the control group from the physical examination center of the Affiliated Hospital of Jining Medical University during the same period as aforementioned, and the individuals were confirmed to exhibit no abnormality by laboratory and imaging examinations. The study protocol and sample collection procedures were approved by the Ethics Committee of the Affiliated Hospital of Jining Medical University and written informed consent was obtained from each participant.

Determination of serum VEGF, TGF- $\beta 1$ and RNF213 levels. Morning fasting blood samples ( $5 \mathrm{ml}$ each) were collected from each subject by elbow venipuncture. Following collection, the samples were left to stand at room temperature for $1 \mathrm{~h}$ and then centrifuged at $3,000 \times \mathrm{g}$ at $4^{\circ} \mathrm{C}$ for $20 \mathrm{~min}$. The supernatant was removed and centrifuged for a second time at $3,000 \mathrm{x} \mathrm{g}$ at $4^{\circ} \mathrm{C}$ for $10 \mathrm{~min}$ to obtain serum, which was stored at $-80^{\circ} \mathrm{C}$ until analysis. The concentrations of VEGF (cat. no. DVE00; R\&D Systems, Inc.), TGF- $\beta 1$ (cat. no. DB100B; R\&D Systems, Inc.) and RNF213 (cat. no. JL19472; Shanghai Jianglai Biological Technology Co., Ltd.; http://www.jonln.com) were determined by ELISA, according to the manufacturer's protocols.

AnimalsandrBMSCculture. A total of 25 male Sprague-Dawley rats (weight, 90-100 g; age, 4 weeks) were purchased from Jinan Pengyue Experimental Animal Breeding, Co., Ltd. The rats were housed under standard conditions of temperature $\left(22 \pm 2^{\circ} \mathrm{C}\right)$, light $(12: 12 \mathrm{~h}$ light/dark cycle) and humidity $(50 \pm 5 \%)$ with free access to food and water. The rats were acclimatized for 7 days before the experiment. All animal procedures were conducted in accordance with Guide for the Care and Use of Laboratory Animals with the approval of Affiliated Hospital of Jining Medical University. rBMSCs were isolated according to the following method. Briefly, the rats were anesthetized by $80 \% \mathrm{CO}_{2}(45 \mathrm{sec})$, sacrificed by cervical dislocation and then immersed in $75 \%$ alcohol for 10 min for disinfection. Following removal of the double lower limb skin, the femur and tibia were aseptically isolated and then soaked in PBS with $1 \%$ penicillin-streptomycin for $1 \mathrm{~min}$. The samples were transferred to $15-\mathrm{ml}$ centrifuge tubes. The ends of the bones were removed and the bone marrow cavities exposed. The marrow cavity was washed 5-10 times with complete medium, namely 89\% Dulbecco's modified Eagle's medium/Nutrient Mixture F-12 medium (Gibco; Thermo Fisher Scientific, Inc.) supplemented with $10 \%$ fetal bovine serum and $1 \%$ penicillin-streptomycin (Gibco; Thermo Fisher Scientific, Inc.) until the medium was clear. All the flushing fluid was then inoculated into a culture flask and incubated at $37^{\circ} \mathrm{C}$ and $5 \% \mathrm{CO}_{2}$. The medium was replaced after $48 \mathrm{~h}$. Based on assessment of proliferation, the medium was changed every 2 days. At $\sim 80 \%$ confluence, the cells were harvested with $0.25 \%$ trypsin-EDTA and sub-cultured at a ratio of 1:2.

Alizarin red and oil red $O$ staining. Cells were seeded into 6-well plates at a density of $2 \times 10^{4}$ cells/well and incubated overnight at $37^{\circ} \mathrm{C}$ with $5 \% \mathrm{CO}_{2}$ in StemXVivo ${ }^{\circledR}$ 
Table I. Primer sequences used for reverse transcription-quantitative PCR analysis.

\begin{tabular}{lll}
\hline Gene & Forward primer sequence (5'-3') & Reverse primer sequence (5'-3)' \\
\hline RNF213 & CAGCGTGTTAGGCAGATCAA & TTGTACTGGCCCTGGTTAGC \\
VEGF & CTGCTGTGGACTTGAGTTGG & CAAACAGACTTCGGCCTCTC \\
TGF-1 $\beta$ & CAATTCCTGGCGTTACCTTG & AGCCCTGTATTCCGTCTCCT \\
-actin & TCAGGTCATCACTATCGGCAAT & AAAGAAAGGGTGTAAAACGCA \\
\hline
\end{tabular}

RNF213, ring finger protein 213; VEGF, vascular endothelial growth factor; TGF- $\beta 1$, transforming growth factor $\beta 1$.

Osteogenic/Adipogenic Base Media (cat. no. CCM007; R\&D Systems, Inc.). After reaching 100\% confluence, the medium was replaced with StemXVivo ${ }^{\circledR}$ Adipogenic Differentiation Media (cat. no. CCM011; R\&D Systems, Inc.) to induce adipogenesis. After reaching $70 \%$ confluence, the medium was replaced with StemXVivo ${ }^{\circledR}$ Osteogenic Differentiation Media (cat. no. CCM009; R\&D Systems, Inc.) to induce osteogenesis. The differentiation medium was replaced every 3 days. After 14 days of adipogenic induction or 21 days of osteogenic induction, MSCs were harvested and fixed with $4 \%$ paraformaldehyde for $30 \mathrm{~min}$ at $4^{\circ} \mathrm{C}$. After washed twice in PBS, cells were stained with Alizarin red (Sigma-Aldrich; Merck KGaA) or oil red O (Sigma-Aldrich; Merck $\mathrm{KGaA}$ ) at room temperature for $30 \mathrm{~min}$ and cells were observed under a light inverted microscope (Olympus IX73; Olympus Corporation).

Flow cytometry analysis. Passage 3 rBMSCs were collected after $0.25 \%$ trypsin (Gibco; Thermo Fisher Scientific, Inc.) treatment and washed with PBS for three times. The cell concentration was adjusted to $1.0 \times 10^{6}$ cells $/ \mathrm{ml}$, and incubated for 25-30 min with antibodies against the following cell surface antigens: CD29 (dilution, 1:50; cat. no. AF2405; R\&D Systems), CD106 (dilution, 1:40; cat. no. ab134047; Abcam), CD34 (dilution, 1:50; cat. no. ab81289; Abcam) and CD45 (dilution, 1:50; cat. no. ab10558; Abcam). Cells were washed three times and incubated with FITC-conjugated anti-goat (dilution, 1:200; cat. no. ab6881; Abcam) or FITC-conjugated anti-rabbit (dilution, 1:200; cat. no. ab6717; Abcam) secondary antibodies. Flow cytometry was performed using a CytoFLEX flow cytometer (Beckman Coulter, Inc.), and the data were analyzed with FlowJo software (version 10.4.2; FlowJo LLC).

Immunofluorescence. Cells were fixed with $4 \%$ paraformaldehyde for $15 \mathrm{~min}$ at room temperature and permeabilized with $0.2 \%$ Triton $\mathrm{X}-100$ for $20 \mathrm{~min}$ at room temperature. After rinsing with PBS, cells were then incubated with CD106 (dilution, 1:200; cat. no. ab134047; Abcam) and CD34 (dilution, 1:200; cat. no. ab81289; Abcam) antibodies for $2 \mathrm{~h}$ at room temperature. After three washes with PBS, cells were incubated with FITC-conjugated anti-rabbit (dilution, 1:200; cat. no. ab6717; Abcam) secondary antibody. DAPI was used for nuclear staining for $3 \mathrm{~min}$ at room temperature. The fluorescence staining was captured with an inverted fluorescence microscope (Olympus IX73; Olympus Corporation).
Lentiviral transfection. pSIH1-H1-copGFP was used to construct the lentiviral vectors. The lentiviral vectors encoding the RNF213 short hairpin RNA (RNF213-shRNA) were designed by Hanbio Biotechnology Co., Ltd. A scramble sequence, named negative-shRNA, was used as the negative control. The rBMSCs were divided into the following three groups: i) RNF213-shRNA; ii) negative-shRNA; and iii) control. The control group was not transfected with plasmids. For lentiviral infection, rBMSCs in the logarithmic growth phase were seeded into 12 -well plates at a density of $5 \times 10^{4}$ cells/well. After $24 \mathrm{~h}$, lentivirus was added at a multiplicity of infection of 100 . The cells were maintained at $37^{\circ} \mathrm{C}$ $\left(5 \% \mathrm{CO}_{2}\right)$ for an additional $24 \mathrm{~h}$, after which the medium was replaced with $1 \mathrm{ml}$ fresh complete medium (containing $10 \%$ fetal bovine serum and $1 \%$ penicillin-streptomycin). The cells were incubated for another $24 \mathrm{~h}$ and then used for further analysis. After 3 days, green fluorescent protein (GFP) expression was assessed using an inverted fluorescence microscope (magnification, x100).

Reverse transcription-quantitative polymerase chain reaction $(R T-q P C R)$. Total RNA was extracted from rBMSCs using an EZ-10 spin column total RNA isolation kit (cat. no. B610583; Sangon Biotech Co., Ltd.), according to the manufacturer's protocol. cDNA was generated using the Quant one step qRT-PCR Kit (cat. no. KR118; Tiangen Biotech Co., Ltd.). The reverse transcription reaction was carried out at $42^{\circ} \mathrm{C}$ for $15 \mathrm{~min}$, followed by $95^{\circ} \mathrm{C}$ for $3 \mathrm{~min}$. qPCR was subsequently performed in a Bio-Rad CFX96 instrument (Bio-Rad Laboratories, Inc.) using a SYBR SuperReal PreMix Plus (cat. no. FP205; Tiangen Biotech Co., Ltd.) and gene-specific primers (Table I). The thermocycling conditions were as follows: Initial denaturation at $95^{\circ} \mathrm{C}$ for $2 \mathrm{~min}$, followed by 40 cycles of amplification at $95^{\circ} \mathrm{C}$ for $10 \mathrm{sec}$ and $60^{\circ} \mathrm{C}$ for 32 sec. $\beta$-actin was used as the internal standard and each cDNA was tested in triplicate. The $2^{-\Delta \Delta \mathrm{Cq}}$ method was used for quantitative analysis (37).

Western blotting $(W B)$. For $\mathrm{WB}$, total protein was isolated from the rBMSCs cells with the use of RIPA and PMSF buffer (Beijing Solarbio Science \& Technology Co., Ltd.) according to the manufacturer's instructions. Protein concentration was determined using the bicinchoninic acid protein assay kit (Beijing Solarbio Science \& Technology Co., Ltd.). The samples were separated by $12 \%$ SDS-PAGE with $\sim 50 \mu \mathrm{g}$ protein in each lane and transferred onto PVDF membranes. 
A

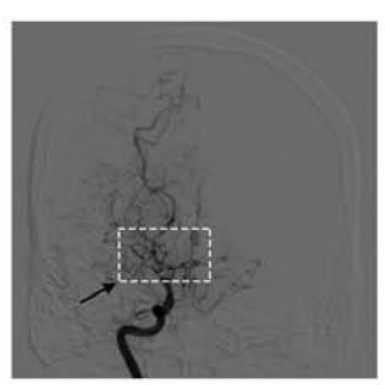

B

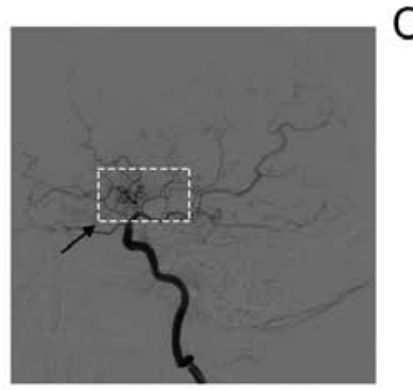

C

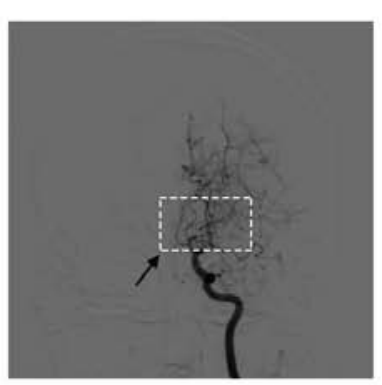

$\mathrm{D}$

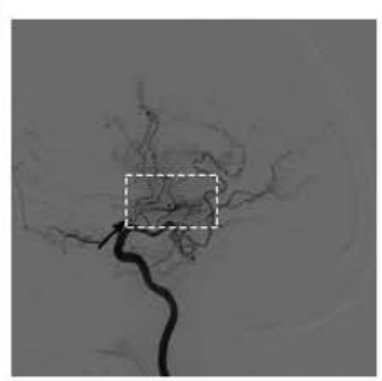

Figure 1. Typical morphology of Moyamoya disease as illustrated by digital subtraction angiography. Representative angiograms of the (A and B) left and (C and D) right internal carotid arteries. The arrow and boxes indicate the smoky appearance of moyamoya vessels.

Table II. Demographic and clinicopathological data of study subjects.

\begin{tabular}{lccc}
\hline Variable & MMD, $\mathrm{n}=40$ & Controls, $\mathrm{n}=40$ & P-value \\
\hline Age, years & $46.6 \pm 9.92$ & $42.6 \pm 12.97$ & $>0.05$ \\
Sex, male/female (n) & $17 / 23$ & $17 / 23$ & $>0.05$ \\
BMI, kg/m ${ }^{2}$ & $23.85 \pm 2.158$ & $24.24 \pm 3.230$ & $>0.05$ \\
Suzuki stage & & & \\
I & 3 & & \\
II & 7 & & \\
III & 13 & & \\
IV & 11 & & \\
V & 6 & & \\
Clinical classification & & & \\
Ischemia & 29 & \\
Hemorrhage & 11 & \\
\hline
\end{tabular}

MMD, Moyamoya disease; BMI, body mass index.

Non-specific binding was blocked by $5 \%$ skimmed milk in TBS-0.1\% Tween-20 (TBST) buffer and incubated overnight at $4{ }^{\circ} \mathrm{C}$ with the following primary antibodies: TGF- $\beta 1$ (dilution, 1:1,000; cat. no. ab215715; Abcam), VEGF (dilution, 1:1,000; cat. no. ab231260; Abcam) and $\beta$-actin (dilution, 1:1,000; cat. no. ab8227; Abcam). Following washing with $0.1 \%$ TBST, the membranes were subsequently probed with horseradish peroxidase-conjugated secondary antibody for $1 \mathrm{~h}$ at room temperature (dilution, 1:2,000; cat. no. ab205718; Abcam). Western blot data were detected using enhanced chemiluminescence solution (Beijing Solarbio Science \& Technology Co., Ltd.) and quantified using ImageJ software (version 1.8.0; National Institutes of Health). $\beta$-actin was used as the loading control.

Statistical analysis. The results are presented as the mean \pm SD and were analyzed using the SPSS statistics software (version 23.0; IBM Corp.). Sex distribution was compared using the $\chi^{2}$ test. Other groups were compared using an independent t-test for normally distributed variables. Differences between groups were assessed by one-way analysis of variance followed by Duncan's test. Pearson correlation analysis was used to analyze the correlation between various factors.
$\mathrm{P}<0.05$ was considered to indicate a statistically significant difference.

\section{Results}

Demographic and clinical characteristics of $M M D$. The typical morphology of MMD, as determined by DSA, is shown in Fig. 1. The demographic and clinical patient characteristics are presented in Table II. The age of MMD onset was 15-61 years, where the hemorrhage types involved included intraventricular, cerebral lobe and subarachnoid; and the ischemic types involved included cerebral infarction and insufficiency of cerebral blood supply. No significant associations in age, sex and body mass index were observed between the healthy control (aged 20-64 years) and MMD groups.

Serum VEGF and TGF- $\beta 1$ levels. For patients with MMD, the VEGF level was $450.06 \pm 299.78 \mathrm{pg} / \mathrm{ml}$, whilst that in the control group was $271.43 \pm 124.42 \mathrm{pg} / \mathrm{ml}$. Similarly, increased levels of TGF- $\beta 1$ were observed in the MMD group, compared with those in the healthy controls (Fig. 2A). The TGF- $\beta 1$ level was $62.93 \pm 12.95 \mathrm{pg} / \mathrm{ml}$ in patients with MMD and $40.08 \pm 8.948 .8$ in the control group (Fig. 2B). Accordingly, the levels of VEGF and TGF- $\beta 1$ were significantly higher in the patient group, as compared with those in the control group ( $\mathrm{P}<0.01$; Fig. 2). The expression levels of RNF213 in the MMD and healthy control groups were also measured. However, there was no difference between the two groups (Fig. S1A). In addition, correlation between RNF213 and TGF- $\beta 1$ in serum was analyzed, where there was no significant correlation (Fig. S1B).

rBMSC morphological alterations and identification. After $12 \mathrm{~h}$ of culture, the rBMSC began to adhere to the culture flask, displayed acceptable proliferation and exhibited a round or fusiform appearance with a clear outline (Fig. S2A). Following culture for $48 \mathrm{~h}$, the rBMSCs exhibited a polyhedral shape with evidence of cell clustering, forming colonies after 3 days (Fig. S2B and C). The number of cell colonies at 4-7 days were gradually increased, where the colony arrangement was vortexor chrysanthemum-shaped, with mutual integration with the neighboring cell colonies observed. At $\sim 8$ days of primary culture, the cell fusion rate had reached $80 \%$ (Fig. 3A and B), where sub-cultured cells proliferated at a higher rate compared with those in the primary culture. After 3-4 days, the cell fusion rate had reached $80-90 \%$. Passage three rBMSCs underwent 

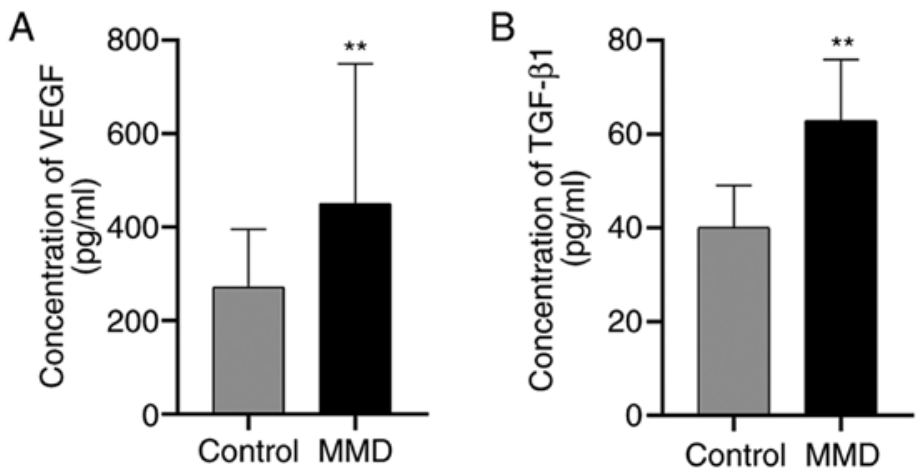

Figure 2. Serum levels of VEGF and TGF- $\beta 1$. Serum was obtained from patients with MMD ( $n=40)$ and healthy subjects ( $n=40)$. (A) VEGF and (B) TGF- $\beta 1$ levels were determined by ELISA. Data are expressed as the mean \pm SD and were analyzed by one-way ANOVA followed by Duncan's test. ${ }^{* *} \mathrm{P}<0.001 \mathrm{vs}$. Control. VEGF, vascular endothelial growth factor; TGF- $\beta 1$, transforming growth factor $\beta 1$; MMD, Moyamoya disease.
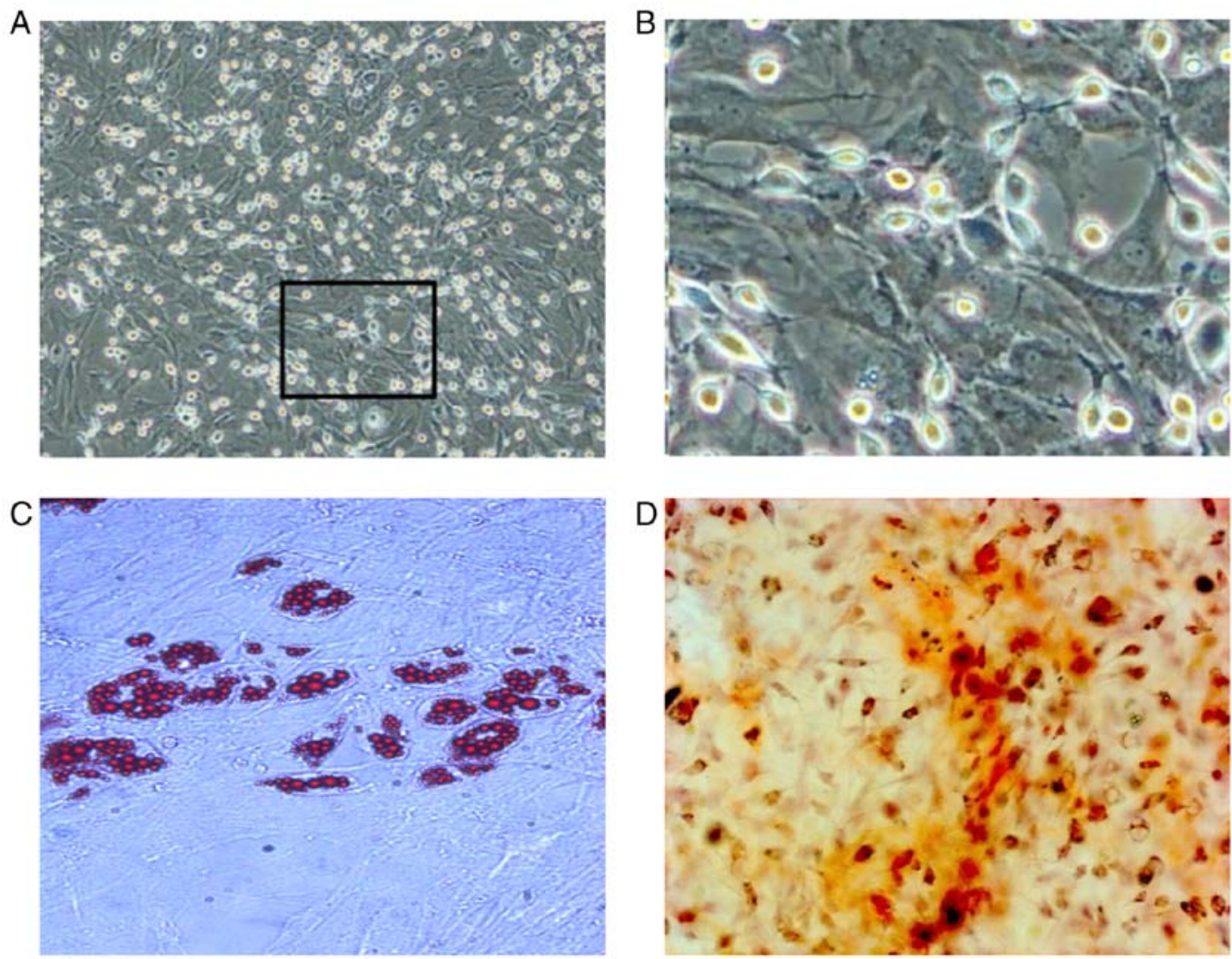

Figure 3. Morphological alterations in rBMSCs. (A) Morphology of rBMSCs on day 8 under magnifications (magnification, x200). (B) Enlarged view of the black box in A (magnification, $\mathrm{x} 400$ ). (C) Passage three rBMSCs were collected and adipogenic differentiation was determined using oil red $\mathrm{O}$ staining (magnification, x400). (D) Osteogenic differentiation of third-passage rBMSCs was determined by Alizarin red staining. rBMSCs, rat bone marrow mesenchymal stem cells (magnification, $\mathrm{x} 200$ ).

adipogenic induction for 14 days, which appeared as red lipid droplets with oil red O staining (Fig. 3C). Osteogenesis was also induced in third-passage rBMSCs for 21 days, presenting as red, clear, densely-calcified nodules following Alizarin red staining (Fig. 3D). Subsequently, flow cytometry confirmed that CD29 (Fig. 4A) and CD106 (Fig. 4B) were positively expressed, with no expression of CD34 (Fig. 4C) and CD45 (Fig. 4D). The immunofluorescence analysis indicated that CD106 were highly expressed, but not CD34 (Fig. 4E). All the results indicated that rBMSCs were successfully isolated in high purity.
RNF213 silencing in rBMSCs. At 2 days post-transfection, the rBMSCs exhibited normal morphology under an optical microscope (Fig. 5A), where the expression of GFP was detected by fluorescence microscopy (Fig. 5B). RNF213 mRNA expression analysis was subsequently conducted. Compared with control group, rBMSCs transfected with RNF213-shRNA displayed a significantly lower RNF213 expression on days 7 and 14, and there was no significant difference between the negative-shRNA and control groups (Fig. 5C). These data suggested that the successful silencing of the RNF213 gene was achieved in rBMSCs. 
A

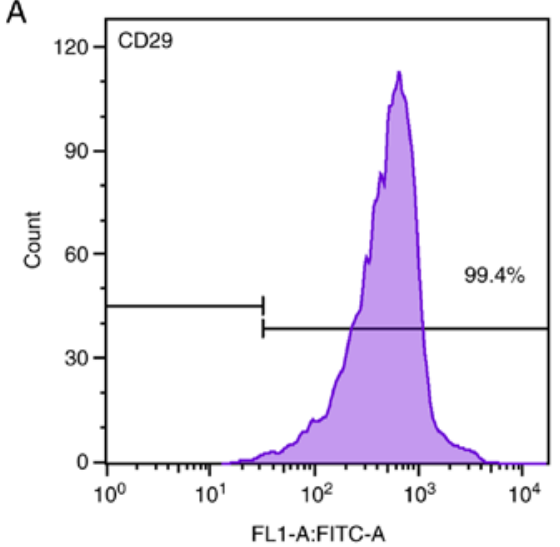

C

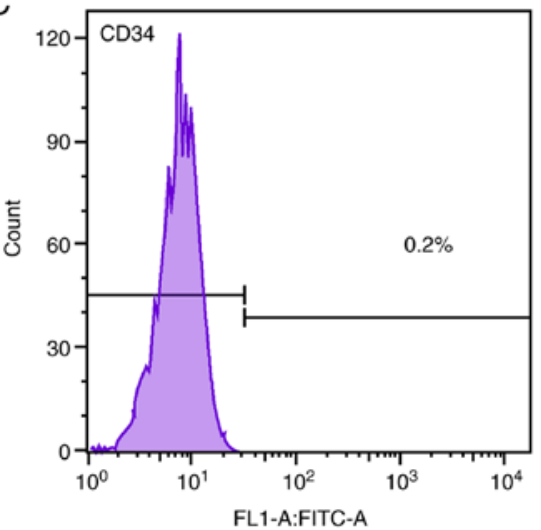

E
B

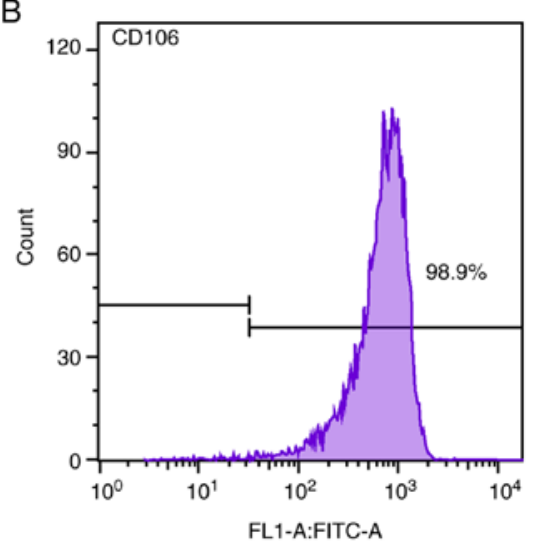

D

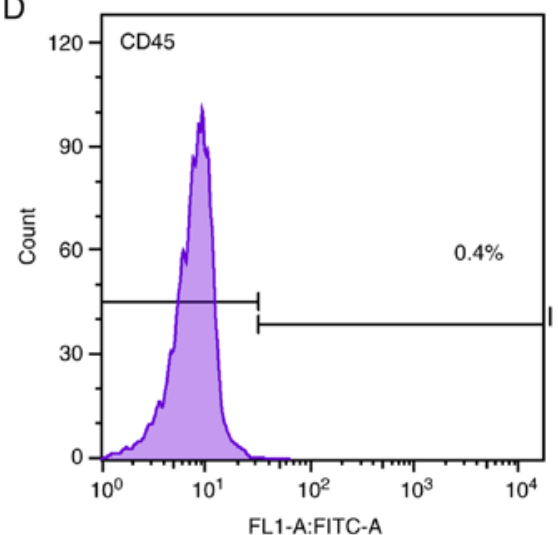

CD34
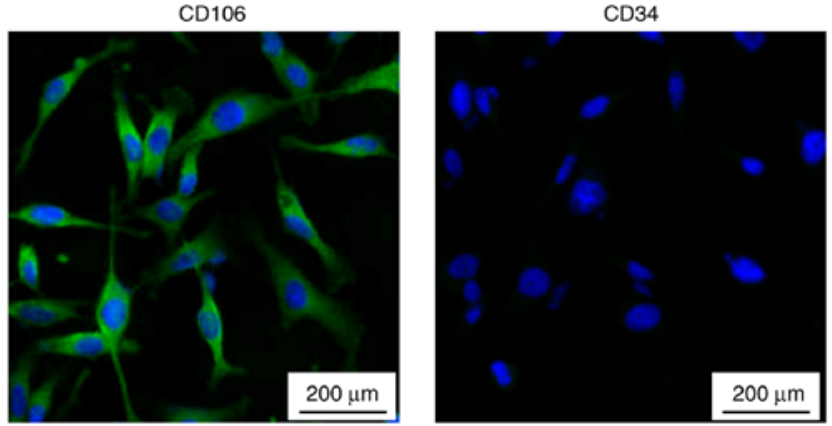

Figure 4. Expression of rat bone marrow mesenchymal stem cell markers, as detected by flow cytometry and immunofluorescence. CD29 and CD106 were positively expressed, whilst no CD34 or CD45 expression was observed. (A) CD29, (B) CD106, (C) CD34 and (D) CD45. (E) Immunofluorescence analysis of CD106 and CD34 expression in rBMSCs (scale bar, $200 \mu \mathrm{m}$ ).
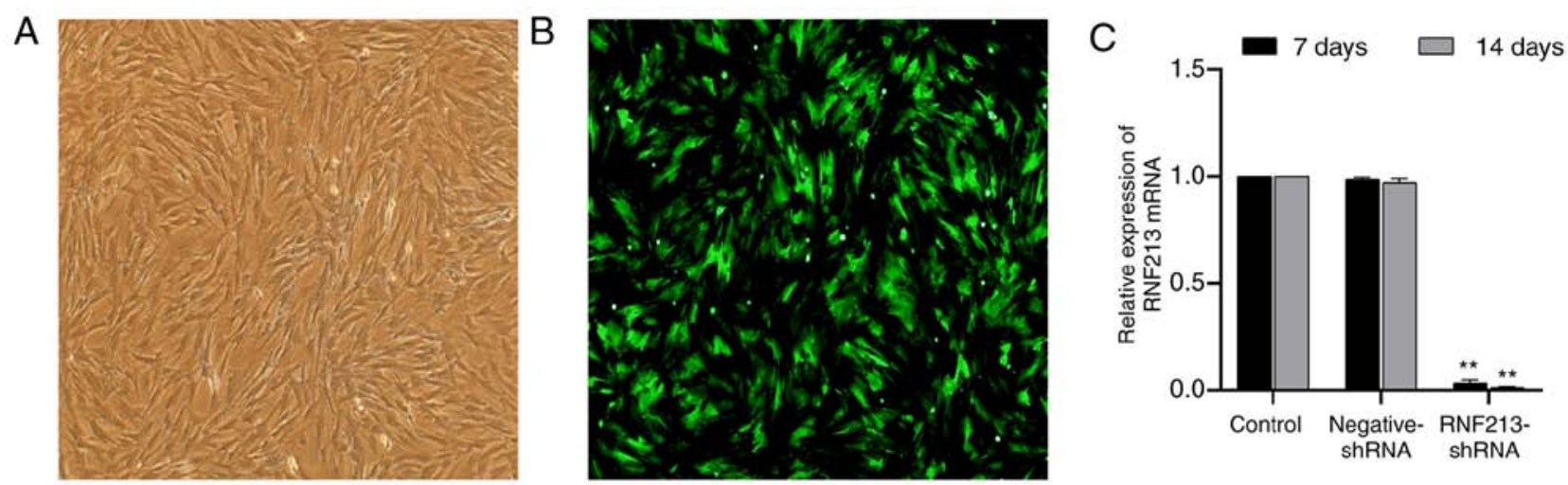

Figure 5. Successful transfection and silencing of RNF213 expression in rBMSCs. (A) Visualization of rBMSCs under normal culture conditions 2 days after the transfection, as determined by optical microscopy (magnification, x100). (B) Expression of green fluorescent protein in rBMSCs 2 days after the transfection under an inverted fluorescence microscope (magnification, x100). (C) Relative RNF213 mRNA levels were determined by reverse transcription quantitative polymerase chain reaction, where $\beta$-actin was used as the internal control. Data are presented as the mean \pm SD and were analyzed by one-way ANOVA followed by Duncan's test. "* $\mathrm{P}<0.001$ vs. Control. RNF213, ring finger protein 213; rBMSCs, rat bone marrow mesenchymal stem cells; shRNA, short harpin RNA. 

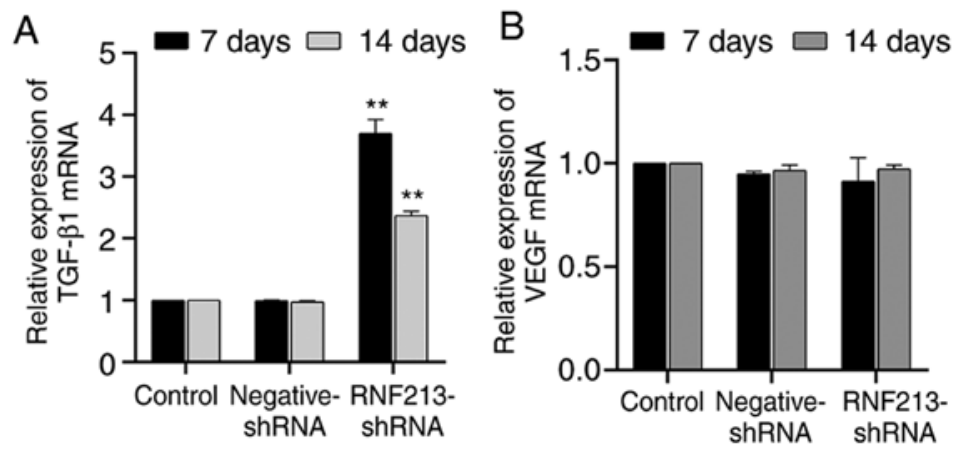

Figure 6. RNF213 silencing increases TGF- $\beta 1$ but not VEGF expression. (A and B) mRNA expression as measured using reverse transcription-quantitative PCR. $\beta$-actin was used as the internal control. (A) TGF- $\beta 1$ mRNA expression in rBMSCs was significantly increased on days 7 and 14 post-RNF213 silencing. (B) VEGF mRNA expression in rBMSCs had not changed on days 7 and 14 post RNF213-silencing. ${ }^{* *}$ P $<0.001$ vs. Control. RNF213, ring finger protein 213; TGF- $\beta 1$, transforming growth factor $\beta 1$; VEGF, vascular endothelial growth factor; rBMSCs, rat bone marrow mesenchymal stem cells; shRNA, short hairpin RNA.

Effects of RNF213 silencing on TGF- $\beta 1$ and VEGF $m R N A$ expression. As shown in Fig. 6, the TGF- $\beta 1$ expression levels in the RNF213-shRNA group were significantly higher compared with those in the control groups, and there was no significant difference between the negative-shRNA and control groups. The expression level of TGF- $\beta 1$ was $>$ three times greater compared with that in the control group on day 7 , and $>$ two times greater compared with that in the control group on day 14 (Fig. 6A). However, no significant differences in the VEGF expression were observed between the RNF213-shRNA and the control groups on both days (Fig. 6B).

Effects of RNF213 knockdown on TGF- $\beta 1$ and VEGF protein expression. RNF213 silencing increased TGF- $\beta 1$ expression, as compared with that in the control group on days 7 and 14 after transfection, respectively, and there was no significant difference between the negative-shRNA and control groups (Fig. 7A, B and D). The VEGF protein expression level in the negative-shRNA group and RNF213-shRNA group did not significantly differ from the control group. (Fig. 7C, E and F).

\section{Discussion}

MMD is a chronic and progressive cerebrovascular occlusion disorder, where the etiology and pathogenic mechanism of which remain poorly understood. The basic pathological feature of MMD is an abnormal vascular network formed at the base of the skull (38). The age of onset distribution for MMD has been suggested to have two peaks, one at 5 and another at $\sim 40$ years of age (39). Regarding gender, two previous studies mentioned the female-to-male ratio. One survey conducted in hospitals throughout Japan reported that the ratio was 1.8 (40), whilst another survey conducted in Hokkaido showed that the ratio was 2.18 (41). Epidemiological analyses have reported distinctive features of familial Moyamoya disease, with the male to female ratio at 5.0 in familial cases (42). Surgical treatment constitutes the main available treatment for MMD with no pharmacological options currently available (43). In a previous study that included 10 years of follow-ups, antiplatelet medications were not found to affect the incidence of cerebral infarction in patients with Moyamoya disease (44). Surgical revascularization is the most successful therapy used to improve cerebral hemodynamics and reduce the risk of subsequent strokes (45). Typical revascularization surgeries for MMD include direct, indirect and combined procedures (46). However, due to the heterogeneity of MMD, the optimal surgical procedures for both ischemic and hemorrhagic MMD remain unclear.

Previous studies have successively determined that VEGF and TGF- $\beta 1$ are abnormally expressed in the plasma of patients with MMD (47-49). To the best of our knowledge, VEGF is the most prominent promoting factor of angiogenesis, with the ability to induce endothelial cell proliferation and increase vascular permeability (50). It has also been reported to stimulate the proliferation of neuronal precursors both in vitro and in vivo (51). Vascular endothelial growth factor is a key positive regulator of both physiological and pathological angiogenesis $(52,53)$. Therefore, VEGF serves an important role in promoting the formation of new 'smoke-like' blood vessels and the establishment of collateral circulation in the brain. Perl et al (54) found that the expression of VEGF and its receptor were significantly increased in the brains of patients with ischemic cerebrovascular disease following long-term ischemia and hypoxia stimulation. In the present study, VEGF was found to be more highly expressed in the serum of patients with MMD compared with that in the control group. This suggests that serum VEGF elevation may be involved in the development of abnormal vascular networks at the base of the brain.

TGF- $\beta 1$ serves an important role in promoting angiogenesis and neuroprotection, in addition to promoting anti-inflammatory and chemotactic processes $(55,56)$. A previous study reported that the delivery of a TGF- $\beta 1$ expression plasmid into the arteries resulted in intimal and medial hyperplasia (57). This phenomenon is similar to the pathological changes observed on the arteries of patients with MMD. The expression of TGF- $\beta 1$ was found to be significantly higher in the superficial temporal artery smooth muscle cells of patients with MMD compared with those in patients with cerebral arteriosclerosis and healthy controls, but, there was no difference in TGF- $\beta 1$ expression in the superficial temporal artery smooth muscle cells between patients with 
A
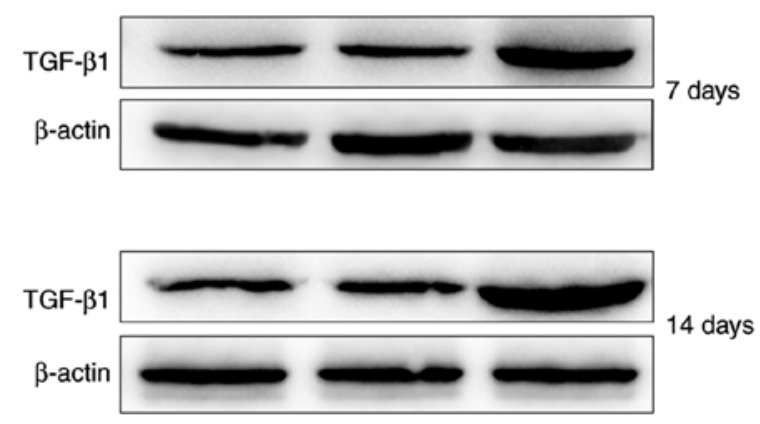

C
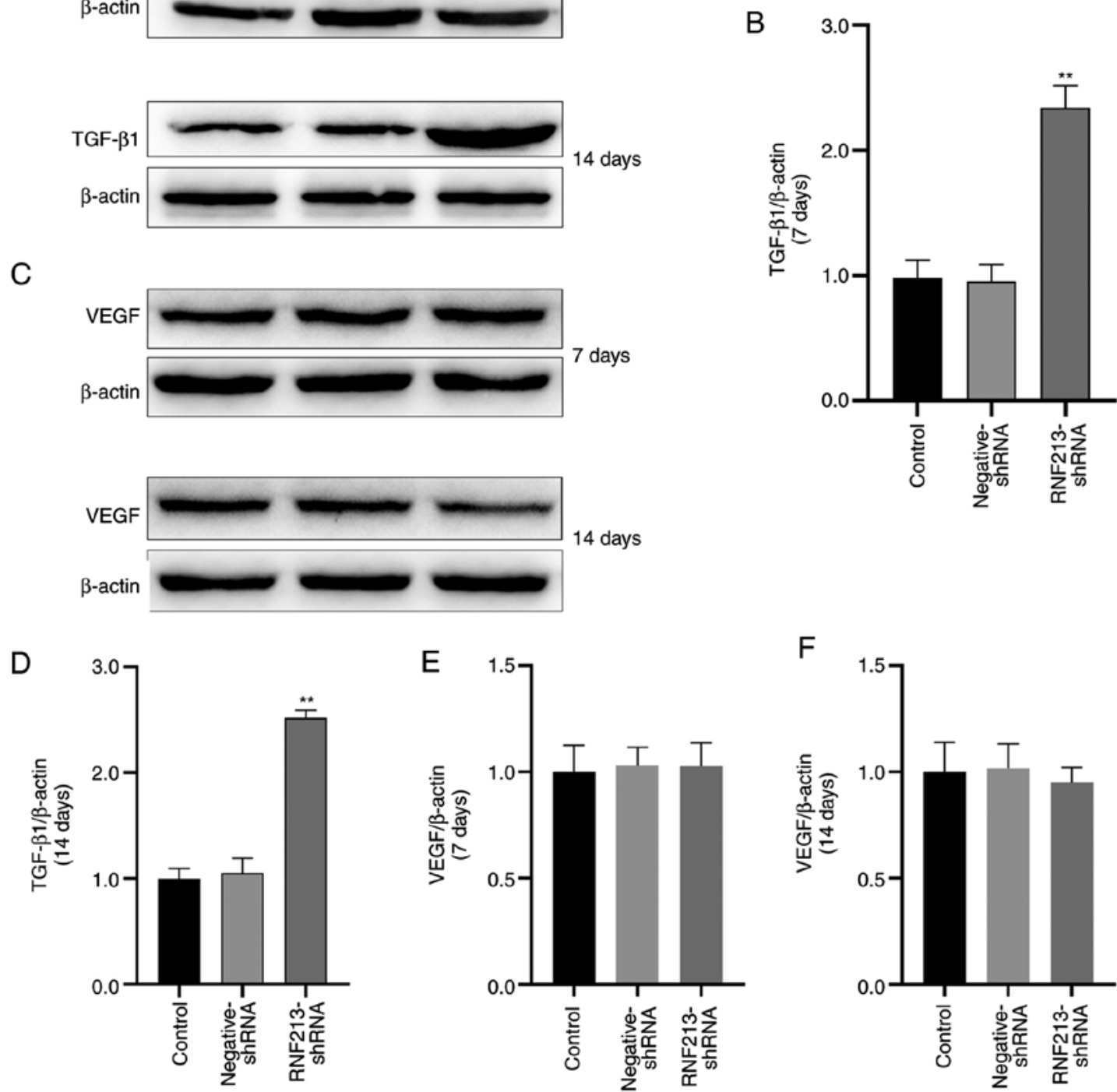

Figure 7. Detection of TGF- $\beta 1$ and VEGF protein levels in rBMSCs following RNF213 silencing. (A) Representative western blotting images of TGF- $\beta 1$ expression 7 and 14 days after transfection. (B) TGF- $\beta 1$ expression 7 days after transfection was quantified. (C) Representative western blotting images of VEGF expression 7 and 14 days after transfection. (D) TGF- $\beta 1$ expression 14 days after transfection was quantified. VEGF expression (E) 7 and (F) 14 days after transfection was quantified. ${ }^{* *} \mathrm{P}<0.001$ vs. Control. TGF- $\beta 1$, transforming growth factor $\beta 1$; VEGF, vascular endothelial growth factor; rBMSCs, rat bone marrow mesenchymal stem cells; RNF213, ring finger protein 213; shRNA, short hairpin RNA.

cerebral arteriosclerosis and healthy individuals (58). These aforementioned studies suggested that TGF- $\beta 1$ promotes angiogenesis and intimal hyperplasia in MMD. The results of the present study revealed that TGF- $\beta 1$ expression was significantly higher in patients with MMD compared with that in healthy individuals, suggesting an influence on the formation of smoke-like blood vessels. The $R N F 213$ gene is a susceptibility gene for MMD, with rs112735431 particularly relevant to the occurrence and development of MMD (59). In addition to rs112735431, numerous variant sites have been identified, including rs148731719, rs371441113 and rs138130613 $(60,61)$. One possible explanation for the lack of a significant correlation between RNF213 and TGF- $\beta 1$ is that RNF213 polymorphism in patients with MMD is a gain-of-function mutation (62).

In scientific research, the use of stably transfected cell lines remains to be the most reliable routine method for delivering genes of interest. Although several types of stem cells, such as embryonic stem cells have also been used, their use comes with several limitations, including the length of time required to obtain a sufficient number of stem cells, as well as legal and ethical restrictions surrounding transplantation and gene therapy (63). Therefore, stem cells do not fully meet current experimental requirements. In this regard, BMSCs were a suitable alternative for the present study, with advantages including a lower rejection rate, convenience and no moral or ethical restrictions (64). It has also been reported that BMSCs can promote central nervous system repair (65). However, there is no standard protocol for the isolation, culture and identification of BMSCs. Currently, four primary methods are used to isolate and purify BMSCs, namely the whole bone marrow adherent method, density gradient centrifugation, flow cytometric separation and immunomagnetic beads (66). Due 
to the indeterminate phenotype and susceptibly of BMSCs to damage, the latter of the two methods are rarely used for practical application (67). Although higher-purity BMSCs can be obtained by density gradient centrifugation, this method is complex in practice and delivers the lowest yield of all four methods (68). Whole bone marrow adhesion is easy to conduct and most accurately simulates the natural BMSC environment (69). Therefore, in the present study, the whole bone marrow adherent method was used to isolate rBMSCs. Currently, there are three methods used to identify MSC (70). In the present study, changes in rBMSC morphology were observed under a microscope, whilst surface antigen expression (CD29, CD106, CD34 and CD45) was assessed by flow cytometry. Furthermore, adipogenic and osteogenic differentiation of rBMSCs was assessed by oil red $\mathrm{O}$ and Alizarin red staining, respectively. The results from the present study indicated that the whole bone marrow adherent method was successfully used to isolate and culture BMSCs in rats.

In the present study, the RNF213 gene was silenced in rBMSCs using lentiviral vectors, which was confirmed by RT-qPCR. The RNF213 gene encodes a 5,256-amino acid protein containing a zinc finger and an ATPase domain, which exhibit E3 ubiquitin ligase and energy-dependent chaperone activities, respectively (71). Previous studies have shown that RNF213 is associated with the onset and severity of MMD and may therefore be a potential marker for the evaluation of MMD prognosis (72-74). Animal experiments have highlighted that the intima-media is more fragile following the ligation of the common carotid arteries in RNF213-knockdown mice compared with that in normal mice, with altered hemodynamics (75). The pathological changes to the lesion vessels in MMD primarily exhibit an irregular smooth muscle cell shape, vacuoles, in addition to fragile vessels with a reduced wall thickness (3). Smooth muscle cell proliferation is the major cause of lesion vessel thickening and medial thinning in patients with MMD (76). Recent data also suggested that various proinflammatory molecules (such as C-reactive protein, interleukin-6) and angiogenic factors are involved in the pathogenesis of MMD $(77,78)$. Combined with suggestions from the present study on MMD etiology, it was hypothesized that the aberrant expression of VEGF and TGF- $\beta 1$ following genetic and/or environmental alterations promotes abnormal smooth muscle cell proliferation, resulting in arterial stenosis and occlusion. This ultimately leads to the clinical symptoms of hemorrhage or ischemia. To verify this speculation, the mRNA expression levels of VEGF and TGF- $\beta 1$ in rBMSCs were determined following RNF213 silencing. The expression of TGF- $\beta 1$ was significantly elevated in RNF213-silenced rBMSCs, supporting the aforementioned hypothesis. RNF213 regulates TGF- $\beta 1$ expression through $\geq$ one pathways, which are also implicated in the occurrence and development of MMD. However, the VEGF expression did not experience significant changes in rBMSCs, rendering association with RNF213 unlikely. It can therefore be concluded that RNF213 may not be the only susceptibility gene for MMD and that VEGF may be involved in the occurrence and development of MMD under the influence of other such genes. Previous studies have identified that MMD patients with the CC genotype of VEGF-634 exhibited an increased collateral vessel formation following surgery (79). An alternative explanation is therefore that VEGF is not involved in the occurrence of MMD but participates in neovascularization following disease onset.

In conclusion, the present study provided evidence that RNF213 silencing influenced TGF- $\beta 1$ expression. The association between RNF213 and the mechanisms of MMD development should be investigated further and applied to MMD screening and gene therapy in the early stages of this disease.

\section{Acknowledgements}

Not applicable.

\section{Funding}

This study was supported by the Key Research and Development Program of Jining Science and Technology (grant no. 2018SMNS005) and the National Natural Science Foundation of China (grant no. 81901954).

\section{Availability of data and materials}

The datasets used and/or analyzed during the current study are available from the corresponding author on reasonable request.

\section{Authors' contributions}

$\mathrm{CW}$ wrote the initial draft of the manuscript. CW, CS, YZ and ZL collected the samples and performed the experiments. HS and ZL supervised the methods of all the experiments and analyzed the data. ZL revised the manuscript. FJ and CC contributed to the conception and design of the study. FJ and $\mathrm{CC}$ confirm the authenticity of all the raw data. All authors read and approved the final version of the manuscript.

\section{Ethics approval and consent to participate}

All participants provided written informed consent for the collection and use of their serum samples. All studies involving animals were performed according to protocols approved by the Ethics Committee of the Affiliated Hospital of Jining Medical University (Jining, China). The ethics reference number was 2020C053.

\section{Patient consent for publication}

Not applicable.

\section{Competing interests}

The authors declare that they have no competing interests.

\section{References}

1. Suzuki J and Takaku A: Cerebrovascular 'moyamoya' disease. Disease showing abnormal net-like vessels in base of brain. Arch Neurol 20: 288-299, 1969.

2. Han W, Jin F, Zhang H, Yang M, Cui C, Wang C and Jiang P: Association of Brain-Gut Peptides with Inflammatory Cytokines in Moyamoya Disease. Mediators Inflamm 2020: 5847478, 2020.

3. Geng C, Cui C, Guo Y, Wang C, Zhang J, Han W, Jin F, Chen D and Jiang P: Metabolomic Profiling Revealed Potential Biomarkers in Patients With Moyamoya Disease. Front Neurosci 14: 308, 2020. 
4. Huang S, Guo Z, Shi M, Yang Y and Rao M: Etiology and pathogenesis of Moyamoya Disease: An update on disease prevalence. Int J Stroke 12: 246-253, 2017.

5. Fang YC, Wei LF, Hu CJ and Tu YK: Pathological Circulating Factors in Moyamoya Disease. Int J Mol Sci 22: 22, 2021.

6. Kapoor S: The genetics of moyamoya disease: Recent insights into the pathogenesis of the disease. Neurosurgery 72: E320-E321, 2013.

7. Roder C, Nayak NR, Khan N, Tatagiba M, Inoue I and Krischek B: Genetics of Moyamoya disease. J Hum Genet 55 711-716, 2010.

8. Yamauchi T, Tada M, Houkin K, Tanaka T, Nakamura Y, Kuroda S, Abe H, Inoue T, Ikezaki K, Matsushima T, et al: Linkage of familial moyamoya disease (spontaneous occlusion of the circle of Willis) to chromosome 17q25. Stroke 31: 930-935, 2000.

9. Sakurai K, Horiuchi Y, Ikeda H,Ikezaki K, Yoshimoto T, Fukui M and Arinami T: A novel susceptibility locus for moyamoya disease on chromosome 8q23. J Hum Genet 49: 278-281, 2004.

10. Inoue TK, Ikezaki K, Sasazuki T, Matsushima T and Fukui M: Linkage analysis of moyamoya disease on chromosome 6 . J Child Neurol 15: 179-182, 2000.

11. Ikeda H, Sasaki T, Yoshimoto T, Fukui $\mathrm{M}$ and Arinami T: Mapping of a familial moyamoya disease gene to chromosome 3p24.2-p26. Am J Hum Genet 64: 533-537, 1999.

12. Kamada F, Aoki Y, Narisawa A, Abe Y, Komatsuzaki S, Kikuchi A, Kanno J, Niihori T, Ono M, Ishii N, et al: A genome-wide association study identifies RNF213 as the first Moyamoya disease gene. J Hum Genet 56: 34-40, 2011.

13. Wang X, Zhang Z, Liu W, Xiong Y, Sun W, Huang X, Jiang Y, Ni G, Sun W, Zhou L, et al: Impacts and interactions of PDGFRB, MMP-3, TIMP-2, and RNF213 polymorphisms on the risk of Moyamoya disease in Han Chinese human subjects. Gene 526 437-442, 2013

14. Ma J, Liu Y, Ma L, Huang S, Li H and You C: RNF213 polymorphism and Moyamoya disease: A systematic review and meta-analysis. Neurol India 61: 35-39, 2013.

15. Wu Z, Jiang H, Zhang L, Xu X, Zhang X, Kang Z, Song D, Zhang J, Guan M and Gu Y: Molecular analysis of RNF213 gene for moyamoya disease in the Chinese Han population. PLoS One 7: e48179, 2012.

16. Liu W, Morito D, Takashima S, Mineharu Y, Kobayashi H, Hitomi T, Hashikata H, Matsuura N, Yamazaki S, Toyoda A, et al: Identification of RNF213 as a susceptibility gene for moyamoya disease and its possible role in vascular development. PLoS One 6: e22542, 2011.

17. Togao O, Mihara F, Yoshiura T, Tanaka A, Kuwabara Y, Morioka T, Matsushima T, Sasaki T and Honda H: Prevalence of stenoocclusive lesions in the renal and abdominal arteries in moyamoya disease. AJR Am J Roentgenol 183: 119-122, 2004.

18. Koizumi A, Kobayashi H, Liu W, Fujii Y, Senevirathna ST, Nanayakkara S, Okuda H, Hitomi T, Harada KH, Takenaka K, et al: P.R4810K, a polymorphism of RNF213, the susceptibility gene for moyamoya disease, is associated with blood pressure. Environ Health Prev Med 18: 121-129, 2013.

19. Liu S, Liu M, Li Q, Liu X, Wang Y, Mambiya M, Zhang K, Yang L, Zhang Q, Shang M, et al: Association of single nucleotide polymorphisms of MTHFR, TCN2, RNF213 with susceptibility to hypertension and blood pressure. Biosci Rep 39: 39, 2019.

20. Nomura S, Aihara Y, Akagawa H, Chiba K, Yamaguchi K, Kawashima A, Okada Y and Kawamata T: Can Moyamoya Disease Susceptibility Gene Affect Extracranial Systemic Artery Stenosis? J Stroke Cerebrovasc Dis 29: 104532, 2020.

21. Wang X, Wang Y, Nie F, Li Q, Zhang K, Liu M, Yang L, Zhang Q, Liu S, Zeng F, et al: Association of Genetic Variants With Moyamoya Disease in 13000 Individuals: A Meta-Analysis. Stroke 51: 1647-1655, 2020.

22. Sun X, Luo M, Li J, Lai R, Lin J, Wang Y, Xu X, Wu S and Sheng W: Prevalence of RNF213 variants in symptomatic intracranial arterial stenosis/occlusion in China. Mol Genet Genomics 295: 635-643, 2020.

23. Wang Y, Zhang Z, Wei L, Zhang Q, Zou Z, Yang L, Li D, Shang M, Han C, Mambiya M, et al: Predictive role of heterozygous p.R4810K of RNF213in the phenotype of Chinese moyamoya disease. Neurology 94: e678-e686, 2020.

24. Smith ER: Moyamoya Biomarkers. J Korean Neurosurg Soc 57 415-421, 2015.

25. Hu JT, Luo J and Chen QX: The Susceptibility Pathogenesis of Moyamoya Disease. World Neurosurg 101: 731-741, 2017.
26. Zhang P, Xing C, Rhodes SD, He Y, Deng K, Li Z, He F, Zhu C, Nguyen L, Zhou Y, et al: Loss of Asxl1 Alters Self-Renewal and Cell Fate of Bone Marrow Stromal Cell, Leading to Bohring-Opitz-like Syndrome in Mice. Stem Cell Reports 6: 914-925, 2016.

27. Hu Y, Li X, Huang G, Wang J and Lu W: Fasudil may induce the differentiation of bone marrow mesenchymal stem cells into neuron like cells via the Wnt/ $\beta$ catenin pathway. Mol Med Rep 19: 3095-3104, 2019.

28. Kawanishi S, Takata $\mathrm{K}$, Itezono $\mathrm{S}$, Nagayama $\mathrm{H}$, Konoya $\mathrm{S}$, Chisaki Y, Toda Y, Nakata S, Yano Y, Kitamura Y, et al: Bone-Marrow-Derived Microglia-Like Cells Ameliorate Brain Amyloid Pathology and Cognitive Impairment in a Mouse Model of Alzheimer's Disease. J Alzheimers Dis 64: 563-585, 2018.

29. Kinnaird T, Stabile E, Burnett MS, Lee CW, Barr S, Fuchs S and Epstein SE: Marrow-derived stromal cells express genes encoding a broad spectrum of arteriogenic cytokines and promote in vitro and in vivo arteriogenesis through paracrine mechanisms. Circ Res 94: 678-685, 2004.

30. Zhu M, Chu Y, Shang Q, Zheng Z, Li Y, Cao L, Chen Y, Cao J, Lee OK, Wang Y, et al: Mesenchymal stromal cells pretreated with pro-inflammatory cytokines promote skin wound healing through VEGFC-mediated angiogenesis. Stem Cells Trans Med 9: 1218-1232, 2020.

31. Zheng Z, Zhang L, Qu Y, Xiao G, Li S, Bao S, Lu QR and Mu D: Mesenchymal Stem Cells Protect Against Hypoxia-Ischemia Brain Damage by Enhancing Autophagy Through Brain Derived Neurotrophic Factor/Mammalin Target of Rapamycin Signaling Pathway. Stem Cells 36: 1109-1121, 2018.

32. Griessenauer CJ, Farrell S, Sarkar A, Zand R, Abedi V, Holland N, Michael A, Cummings CL, Metpally R, Carey DJ, et al: Genetic susceptibility to cerebrovascular disease: A systematic review. J Cereb Blood Flow Metab 38: 1853-1871, 2018.

33. Stienen MN, Smoll NR, Weisshaupt R, Fandino J, Hildebrandt G, Studerus-Germann A and Schatlo B: Delayed cerebral ischemia predicts neurocognitive impairment following aneurysmal subarachnoid hemorrhage. World Neurosurg 82: e599-e605, 2014.

34. Baek HJ, Chung SY, Park MS, Kim SM, Park KS and Son HU: Preliminary study of neurocognitive dysfunction in adult moyamoya disease and improvement after superficial temporal artery-middle cerebral artery bypass. J Korean Neurosurg Soc 56: 188-193, 2014

35. Li F, Zhang J, Liao R, Duan Y, Tao L, Xu Y and Chen A: Mesenchymal stem cell derived extracellular vesicles prevent neural stem cell hypoxia injury via promoting miR-210-3p expression. Mol Med Rep 22: 3813-3821, 2020.

36. Research Committee on the Pathology and Treatment of Spontaneous Occlusion of the Circle of Willis; Health Labour Sciences Research Grant for Research on Measures for Infractable Diseases: Guidelines for diagnosis and treatment of moyamoya disease (spontaneous occlusion of the circle of Willis). Neurol Med Chir (Tokyo) 52: 245-266, 2012.

37. Livak KJ and Schmittgen TD: Analysis of relative gene expression data using real-time quantitative PCR and the 2(-Delta Delta C(T)) Method. Methods 25: 402-408, 2001

38. Fujimura $M$ and Tominaga T: Significance of Cerebral Blood Flow Analysis in the Acute Stage after Revascularization Surgery for Moyamoya Disease. Neurol Med Chir (Tokyo) 55: 775-781, 2015.

39. Lee JS, Hong JM, Moon GJ, Lee PH, Ahn YH and Bang OY; STARTING collaborators: A long-term follow-up study of intravenous autologous mesenchymal stem cell transplantation in patients with ischemic stroke. Stem Cells 28: 1099-1106, 2010.

40. Wakai K, Tamakoshi A, Ikezaki K, Fukui M, Kawamura T, Aoki R, Kojima M, Lin Y and Ohno Y: Epidemiological features of moyamoya disease in Japan: Findings from a nationwide survey. Clin Neurol Neurosurg 99 (Suppl 2): S1-S5, 1997.

41. Baba T, Houkin K and Kuroda S: Novel epidemiological features of moyamoya disease. J Neurol Neurosurg Psychiatry 79: 900-904, 2008

42. Kuroda S and Houkin K: Moyamoya disease: Current concepts and future perspectives. Lancet Neurol 7: 1056-1066, 2008.

43. Mayeku J and Lopez-Gonzalez MA: Current Surgical Options for Moyamoya Disease. Cureus 12: e11332, 2020.

44. Yamada S, Oki K, Itoh Y, Kuroda S and Suzuki N: Effects of Surgery and Antiplatelet Therapy in Ten-Year Follow-Up from the Registry Study of Research Committee on Moyamoya Disease in Japan. J Stroke Cerebrovasc Dis 25: 340-349, 2016. 
45. Arias EJ, Derdeyn CP, Dacey RG and Zipfel GJ: Advances and surgical considerations in the treatment of moyamoya disease. Neurosurgery 74 (Suppl 1): S116-125, 2014.

46. Tokairin K, Kazumata K, Gotoh S, Sugiyama T and Kobayashi H: Neuroendoscope-Assisted Aneurysm Trapping for Ruptured Intraventricular Aneurysms in Moyamoya Disease Patients. World Neurosurg 141: 278-283, 2020.

47. Kang HS, Kim JH, Phi JH, Kim YY, Kim JE, Wang KC, Cho BK and Kim SK: Plasma matrix metalloproteinases, cytokines and angiogenic factors in moyamoya disease. J Neurol Neurosurg Psychiatry 81: 673-678, 2010.

48. Sakamoto S, Kiura Y, Yamasaki F, Shibukawa M, Ohba S, Shrestha P, Sugiyama K and Kurisu K: Expression of vascular endothelial growth factor in dura mater of patients with moyamoya disease. Neurosurg Rev 31: 77-81, discussion 81, 2008

49. Yamamoto M, Aoyagi M, Tajima S, Wachi H, Fukai N, Matsushima Y and Yamamoto K: Increase in elastin gene expression and protein synthesis in arterial smooth muscle cells derived from patients with Moyamoya disease. Stroke 28 : 1733-1738, 1997.

50. Ng YS, Krilleke D and Shima DT: VEGF function in vascular pathogenesis. Exp Cell Res 312: 527-537, 2006.

51. Jin K, Zhu Y, Sun Y, Mao XO, Xie L and Greenberg DA: Vascular endothelial growth factor (VEGF) stimulates neurogenesis in vitro and in vivo. Proc Natl Acad Sci USA 99: 11946-11950, 2002.

52. Fujii T, Yonemitsu Y, Onimaru M, Inoue M, Hasegawa M, Kuwano $\mathrm{H}$ and Sueishi K: VEGF function for upregulation of endogenous PIGF expression during FGF-2-mediated therapeutic angiogenesis. Atherosclerosis 200: 51-57, 2008.

53. Chen CY, Rao SS, Ren L, Hu XK, Tan YJ, Hu Y, Luo J, Liu YW, Yin H, Huang J, et al: Exosomal DMBT1 from human urine-derived stem cells facilitates diabetic wound repair by promoting angiogenesis. Theranostics 8: 1607-1623, 2018.

54. Perl M, Chung CS and Ayala A: Apoptosis. Crit Care Med 33 (Suppl): S526-S529, 2005.

55. Kim DW, Jo YY, Garagiola U, Choi JY, Kang YJ, Oh JH and Kim SG: Increased Level of Vascular Endothelial Growth Factors by 4-hexylresorcinol is Mediated by Transforming Growth Factor- $\beta 1$ and Accelerates Capillary Regeneration in the Burns in Diabetic Animals. Int J Mol Sci 21: 21, 2020.

56. König HG, Kögel D, Rami A and Prehn JH: TGF- $\{$ beta 1 activates two distinct type I receptors in neurons: Implications for neuronal NF-\{kappa\}B signaling. J Cell Biol 168: 1077-1086, 2005.

57. Nabel EG, Shum L, Pompili VJ, Yang ZY, San H, Shu HB, Liptay S, Gold L, Gordon D and Derynck R: Direct transfer of transforming growth factor beta 1 gene into arteries stimulates fibrocellular hyperplasia. Proc Natl Acad Sci USA 90: 10759-10763, 1993.

58. Hojo M, Hoshimaru M, Miyamoto S, Taki W, Nagata I, Asahi M, Matsuura N, Ishizaki R, Kikuchi $\mathrm{H}$ and Hashimoto N: Role of transforming growth factor- $\beta 1$ in the pathogenesis of moyamoya disease. J Neurosurg 89: 623-629, 1998.

59. Huang Y, Cheng D, Zhang J and Zhao W: Association between the rs112735431 polymorphism of the RNF213 gene and moyamoya disease: A case-control study and meta-analysis. J Clin Neurosci 32: 14-18, 2016.

60. Park MG, Shin JH, Lee SW, Park HR and Park KP: RNF213 rs112735431 polymorphism in intracranial artery steno-occlusive disease and moyamoya disease in Koreans. J Neurol Sci 375: 331-334, 2017.

61. Zhang Q, Liu Y, Zhang D, Wang R, Zhang Y, Wang S, Yu L, Lu C, Liu F, Zhou J, et al: RNF213 as the major susceptibility gene for Chinese patients with moyamoya disease and its clinical relevance. J Neurosurg 126: 1106-1113, 2017.

62. Hitomi T, Habu T, Kobayashi H, Okuda H, Harada KH, Osafune K, Taura D, Sone M, Asaka I, Ameku T, et al: The moyamoya disease susceptibility variant RNF213 R4810K (rs112735431) induces genomic instability by mitotic abnormality. Biochem Biophys Res Commun 439: 419-426, 2013.

63. Liu G, Beggs H, Jürgensen C, Park HT, Tang H, Gorski J, Jones KR, Reichardt LF, Wu J and Rao Y: Netrin requires focal adhesion kinase and Src family kinases for axon outgrowth and attraction. Nat Neurosci 7: 1222-1232, 2004.
64. Abe K, Yamashita T, Takizawa S, Kuroda S, Kinouchi H and Kawahara N: Stem cell therapy for cerebral ischemia: From basic science to clinical applications. J Cereb Blood Flow Metab 32: 1317-1331, 2012

65. Harris VK, Yan QJ, Vyshkina T, Sahabi S, Liu X and Sadiq SA Clinical and pathological effects of intrathecal injection of mesenchymal stem cell-derived neural progenitors in an experimental model of multiple sclerosis. J Neurol Sci 313: 167-177, 2012.

66. Gamie Z, Tran GT, Vyzas G, Korres N, Heliotis M, Mantalaris A and Tsiridis E: Stem cells combined with bone graft substitutes in skeletal tissue engineering. Expert Opin Biol Ther 12: 713-729, 2012.

67. Deryugina EI and Müller-Sieburg CE: Stromal cells in long-term cultures: Keys to the elucidation of hematopoietic development? Crit Rev Immunol 13: 115-150, 1993.

68. Lisignoli G, Remiddi G, Cattini L, Cocchini B, Zini N, Fini M, Grassi F, Piacentini A and Facchini A: An elevated number of differentiated osteoblast colonies can be obtained from rat bone marrow stromal cells using a gradient isolation procedure. Connect Tissue Res 42: 49-58, 2001.

69. Li YH, Wang ZD, Wang W, Ding CW, Zhang HX and Li JM: The biocompatibility of calcium phosphate cements containing alendronate-loaded PLGA microparticles in vitro. Exp Biol Med (Maywood) 240: 1465-1471, 2015.

70. Dominici M, Le Blanc K, Mueller I, Slaper-Cortenbach I, Marini F, Krause D, Deans R, Keating A, Prockop Dj and Horwitz E: Minimal criteria for defining multipotent mesenchymal stromal cells. The International Society for Cellular Therapy position statement. Cytotherapy 8: 315-317, 2006.

71. Moteki Y, Onda H, Kasuya H, Yoneyama T, Okada Y, Hirota K, Mukawa M, Nariai T, Mitani S and Akagawa H: Systematic Validation of RNF213 Coding Variants in Japanese Patients With Moyamoya Disease. J Am Heart Assoc 4: e001862, 2015.

72. Bang OY, Ryoo S, Kim SJ, Yoon CH, Cha J, Yeon JY, Kim KH, Kim GM, Chung CS, Lee KH, et al: Adult Moyamoya Disease: A Burden of Intracranial Stenosis in East Asians? PLoS One 10: e0130663, 2015

73. Nomura S, Yamaguchi K, Akagawa H, Kawashima A, Moteki Y, Ishikawa T, Aihara Y, Saito T, Okada Y and Kawamata T: Genotype-Phenotype Correlation in Long-Term Cohort of Japanese Patients with Moyamoya Disease. Cerebrovasc Dis 47: 105-111, 2019.

74. Kim EH, Yum MS, Ra YS, Park JB, Ahn JS, Kim GH, Goo HW, Ko TS and Yoo HW: Importance of RNF213 polymorphism on clinical features and long-term outcome in moyamoya disease. J Neurosurg 124: 1221-1227, 2016.

75. Fujimura M, Sonobe S, Nishijima Y, Niizuma K, Sakata H, Kure $\mathrm{S}$ and Tominaga T: Genetics and Biomarkers of Moyamoya Disease: Significance of RNF213 as a Susceptibility Gene. J Stroke 16: 65-72, 2014

76. Reid AJ, Bhattacharjee MB, Regalado ES, Milewicz AL, El-Hakam LM, Dauser RC and Milewicz DM: Diffuse and uncontrolled vascular smooth muscle cell proliferation in rapidly progressing pediatric moyamoya disease. J Neurosurg Pediatr 6: 244-249, 2010

77. Han W, Qiao Y, Zhang H, Geng C, Zhu X, Liao D, Guo Y, Yang M, Chen D and Jiang P: Circulating sortilin levels are associated with inflammation in patients with moyamoya disease. Metab Brain Dis 36: 103-109, 2021.

78. Corey S and Luo Y: Circular RNAs and neutrophils: Key factors in tackling asymptomatic moyamoya disease. Brain Circ 5: $150-155,2019$.

79. Park YS, Jeon YJ, Kim HS, Chae KY, Oh SH, Han IB, Kim HS, Kim WC, Kim OJ, Kim TG, et al: The role of VEGF and KDR polymorphisms in moyamoya disease and collateral revascularization. PLoS One 7: e47158, 2012.

This work is licensed under a Creative Commons Attribution-NonCommercial-NoDerivatives 4.0 International (CC BY-NC-ND 4.0) License. 